\title{
Study and Implementation of a Computational Platform to Drive a Switched Reluctance Motor 8x6 for Electric Vehicles Applications
}

\author{
M.B.S.Pinto ${ }^{1}$, G.P.Viajante ${ }^{1}$,M.E.Oliveira, E.N.Chaves and M.A.A.Freitas \\ ${ }^{1}$ Federal Institute of Education, Science and Technology of Goiás \\ Campus of Itumbiara - Goiás, (Brazil) \\ Phone/Fax number: +55 62 xx, e-mail: $\underline{\text { mathheusbueno@gmail.com, ghunterp@gmail.com }}$
}

\begin{abstract}
This paper aims to develop a computational platform for study and analysis of a Switched Reluctance Machine (SRM) $8 \times 6$ operating as motor for electric vehicles applications. In SRM modelling it was used the non-linear approach, which includes the representation of the magnetic circuit saturation through the concept of incremental inductance. For machine drive is used the topology of the asymmetrical half-bridge converter. The proposal is to make the computational representation to simulate of the behaviour of this machine under several operations conditions, guaranteeing safety and reliability of the results. Besides the drive of the SRM, the computational platform allows the study of the various magnitudes and aspects of this machine, such as: inductance, torque, speed profile, power and efficiency. A current control is also implemented, and simulation results are presented and discussed.
\end{abstract}

\section{Keywords}

Electric vehicles, Energy efficiency, Switched Reluctance Motor 8x6.

\section{Introduction}

It has record that the first Switched Reluctance Machine was developed and had its application around 1838 in Scotland, and it was used in a locomotive [1]. Although its record is old, its development has been slowed down due to the electronic dependencies required to carry out its control. Due to the great advance in the latest decades of the electrical engineering, such as microcontrollers, electronic components, control systems among others; Many machines are becoming increasingly accessible, as the Switched Reluctance Machine (SRM) [2].

In this machine it is verified that its inductance varies according to the position of the rotor relative to its stator, it presents the minimum inductance when the poles are misaligned one relative to the other, and maximum inductance when the poles of them are fully Aligned. These positions can be classified as position of imbalance and equilibrium, respectively [3].

The Figure 1 shows the cross section of a motor containing the rotor and stator. Feeding the phase of the machine when it is in the equilibrium position there will be no movement, because the Poles are already aligned. However, when feeding the phase of the machine in the when it is in the position of imbalance, the rotor tended to move either clockwise or counter clockwise seeking maximum inductance, equilibrium position.

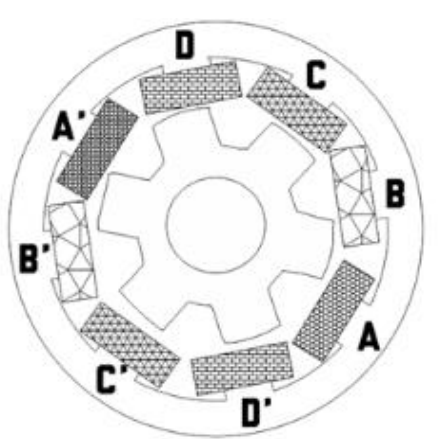

Fig. 1. Equivalent circuit for one phase.

The machine has already been used in electric vehicles, such as the Land Rover Defender 110, which was developed by Jaguar Land Rover in 2013. It replaced its diesel engine with a SRM of $70 \mathrm{~kW}$, powered by a 300 volt lithium-ion battery with a capacity of $27 \mathrm{kWh}$ that was able to have a range of $80 \mathrm{~km}$ and can reach $110 \mathrm{~km} / \mathrm{h}$ with a fully charged battery [4][5].

Applications such as hybrid traction coupled with optimization techniques, aiming to optimize torque, to use power generation in braking to reduce machine losses are shown to be viable for the machine [6][7]. A promising application is its use in urban buses, as these vehicles have a high pollution index and low efficiency due to their topology of operation. This technology reduces the emission of gases pollutants and reduces the consumption of fossil fuels [8][9]. We can also use the machine generator function, by charging the batteries and providing greater autonomy for the vehicle.

\section{Mathematical Model Switched Reluctance Machine}

Based on the equations that describe the behavior of the engine the Switched Reluctance is used a model available in the MATLAB ${ }^{\mathrm{TM}} / \operatorname{simulink}{ }^{\circledR}$ platform, to express the whole system of equation and activation of the same.

For the development of this mathematical modeling was considered the Switched Reluctance $8 \times 6$ operating as 
a motor, with four phases, from which was performed the integration of the state matrix of the same. The complete development of the equations was not approached because it escapes the intention of it. Below in Figure 2 we have the representation of the circuit for a phase of the machine.

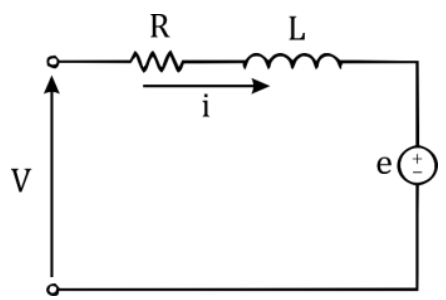

Fig. 2. Equivalent circuit for one phase of the Switched Reluctance Machine

Initially, we can consider the equation of a phase of the reluctance machine and expressed by:

$$
v=R i+L(i, \theta) \frac{d i}{d t}+e
$$

Where, $\mathrm{V}$ is the voltage in the phase of the machine, $\boldsymbol{R}$ is the phase resistance, $\boldsymbol{i}$ is the phase current, $\boldsymbol{L}(\boldsymbol{i}, \boldsymbol{\theta})$ is the inductance of the phase which depends on the position of the rotor and the phase current and is the force against electromotive.

The force against Electromotive can be written by:

$$
e=i \omega \frac{d L(i, \theta)}{d \theta}
$$

Where, $\boldsymbol{\omega}$ is the mechanical angular velocity of the shaft. The mechanical equation of the machine can be obtained from the analysis of its movement dynamics. We can define the equation of the mechanical engine conjugate that can be expressed by:

$$
T_{m}=T_{e m a g}-D \omega-J \frac{d \omega}{d t}
$$

Where, $\boldsymbol{T}_{\boldsymbol{m}}$ is the mechanical conjugate, $\boldsymbol{T}_{\boldsymbol{e m a g}}$ is the electromagnetic conjugate, $\omega$ is the angular velocity, $\boldsymbol{J}$ is the moment of inertia and $\boldsymbol{D}$ is the coefficient of viscous friction.

Using the equations of electrical and mechanical behavior of the Switched Reluctance Machine acting as motor. Reorganizing the equations and rewriting in the matrix form, equation 4, so that it facilitates the calculations for its solution [10].

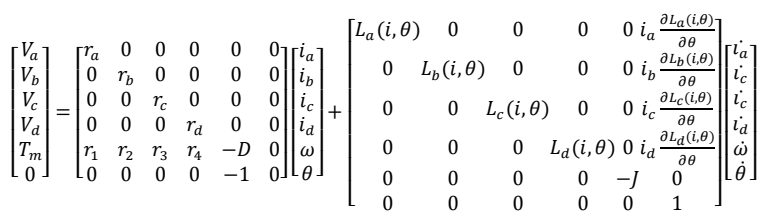

$$
\begin{aligned}
& r_{1}=\frac{1}{2} \cdot i_{a} \frac{\partial L_{a}(i, \theta)}{\partial \theta}, r_{2}=\frac{1}{2} \cdot i_{b} \frac{\partial L_{b}(i, \theta)}{\partial \theta}, r_{3}=\frac{1}{2} \cdot i_{c} \frac{\partial L_{c}(i, \theta)}{\partial \theta}, r_{4}=\frac{1}{2} \cdot i_{d} \frac{\partial L_{d}(i, \theta)}{\partial \theta}
\end{aligned}
$$

From the matrix of States, Equation 4, we can define the equation of states, Equation 5, which allows the complete description of the behavior of each phase of the machine at any time.

$$
[\dot{I}]=[L]^{-1}[V]-[L]^{-1}[R][I]
$$

Through the data of this matrix and an existing base on the MATLAB $^{\mathrm{TM}} /$ simulink ${ }^{\circledR}$ platform, we started to develop the drive platform.

\section{Simulation of the Switched Reluctance Motor}

The simulation was implemented in environment from a mathematical model developed specifically to represent this machine, Figure 3 shows the summary diagram of the simulation.

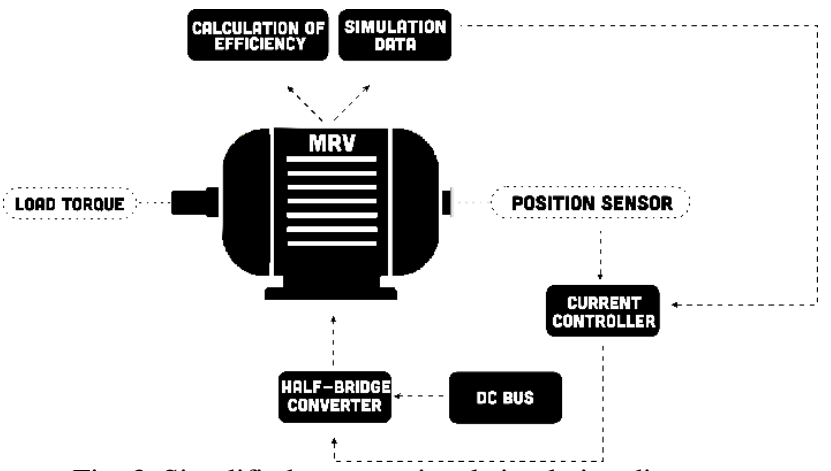

Fig. 3. Simplified computational simulation diagram.

The simulation utilizes the half-bridge converter topology that uses IGBT (Insulated Gate Bipolar Transistor) type keys and each phase of the machine uses two keys that correspond to one arm of the converter. The converter receives the drive signals from the current controller and the position sensor, and it is fed with a voltage supplied by the DC Bus producing a magnitude of current and voltage for each of the engine phases. The converter contains a drive circuit for each engine arm, enabling an individual drive of each phase of the engine.

The arms contain identical drive circuits being implemented depending on the type of simulation. It is a physical model, as well as in a real circuit, the inputs are the voltage terminals of the source and the drive signals, while the output is a current and voltage applied to the engine. Phase winding terminals, the one-phase diagram can be checked in Figure 4.

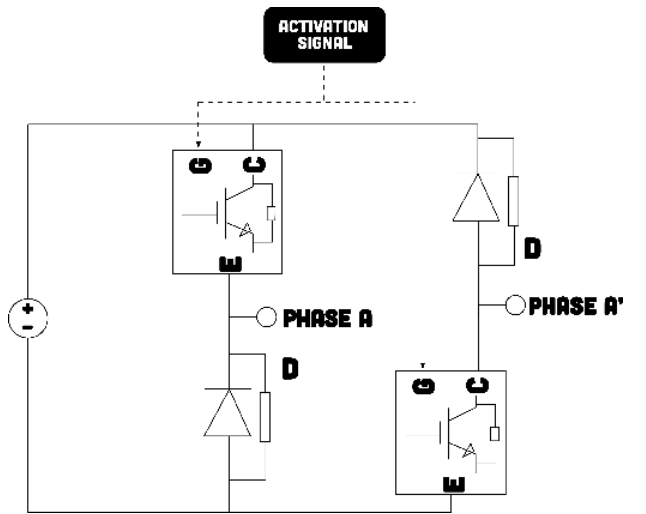

Fig. 4. Simplified computational simulation diagram. 
The model represents the logic of controlling and triggering a real system. These blocks are the position and phase detection activation block, the current control block, and the phase angle controller block. Each of these is implemented using the basic logic of Simulink.

\section{A. Position Sensor}

The position sensor block estimates the position of the rotor based on the motor speed, comparing this position with the phase angle limits established by the phase angle controller is performing the phase activation. If the poles are aligning with a phase, this phase becomes active, generating a trigger signal to the converter key according to the position the phase is in, and it remains so until the phase begins to misalign or the angle of disconnection. Once the disconnection angle is turned off the converter key.

\section{B. Efficiency}

The efficiency is calculated in a specific block, its model is represented by Figure 5, where the input power is calculated by the product of the current and the voltage of the converter, the output power is taken from the product of the torque and the speed of the engine, is integrated with each motor cycle.

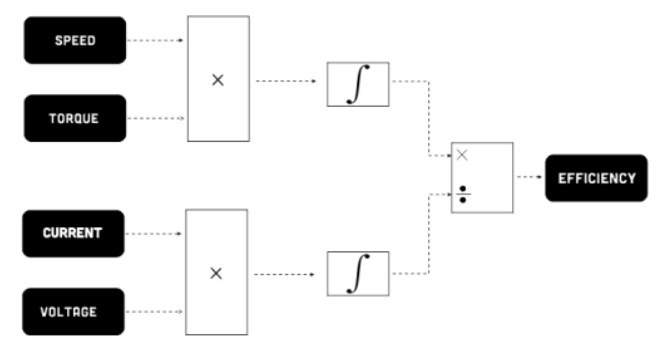

Fig. 5. Diagram of the efficiency calculation block.

\section{Current control of the fases}

Current control is implemented using the "Relay" block, available on the simulink platform. In the control is using a reference current and multiplying it by the signal of the activation of the phase; therefore, if a phase is inactive, the reference current is zero. The difference between the phase activation current and the current feedback signal for the respective phase is the current error for this phase. The current error is passed through the relay block, which determines whether it is above or below the desired threshold around the reference current input error. The signal is then sent to drive the converter keys, activating if the current is below the limit and deactivating if the current is above the limit. The diagram of this block is shown in Figure 6.

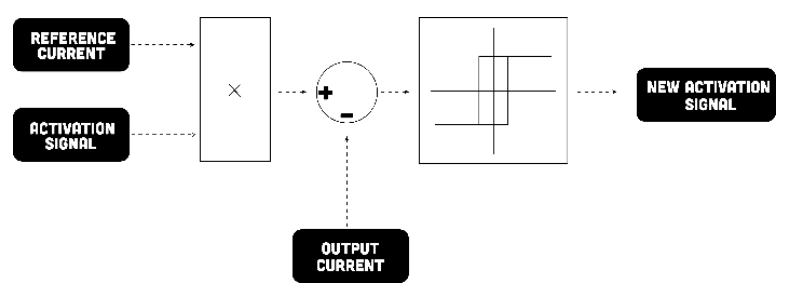

The following will be shown several graphs that validate the experimental simulation. At first it is shown the speed of the motor shaft in permanent regime which is approximately $157 \mathrm{rad} / \mathrm{s}$, this using the motor without load on the axle. In Figure 7 we have the behaviour of motor speed showing the complete period, transient and permanent regime.

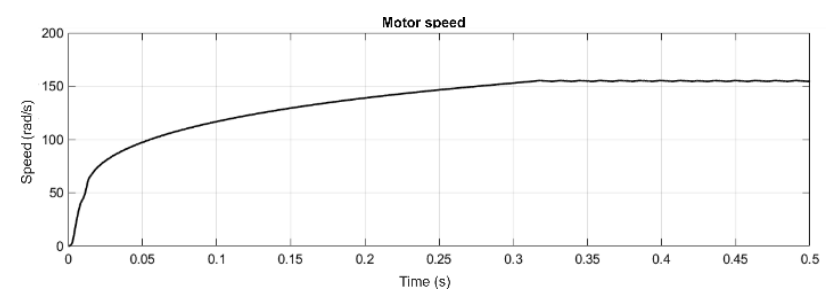

Fig. 7. Motor speed in transient regime and permanent regime.

Figure 8 shows the current in each phase of the motor for the transient regime already Figure 8 shows for the permanent regime. We can observe in the figures the control acting on the current. During the transitional regime, the control by hysteresis and activated by causing the control of the current through switching of the IGBTs and this occurs until the machine reaches the permanent regime, the control range is defined in the current controller block.

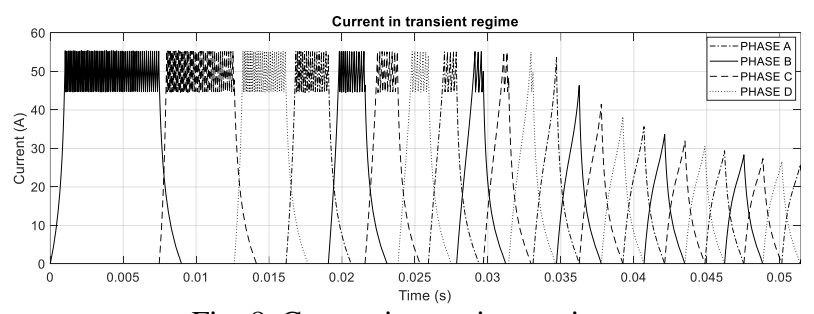

Fig. 8. Current in transient regime.

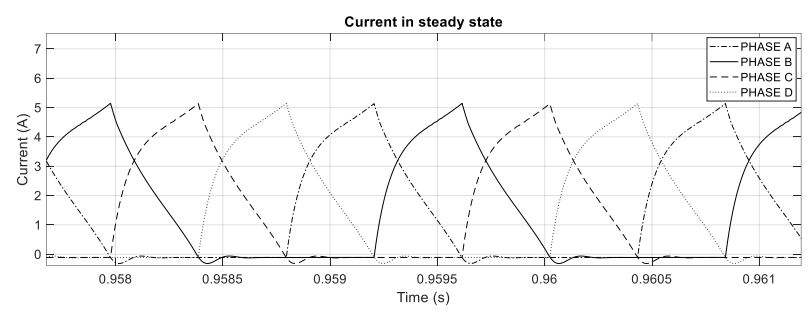

Fig. 9. Current in steady state.

In figure 10 we have the behavior of the motor torque to variable reluctance in steady state.

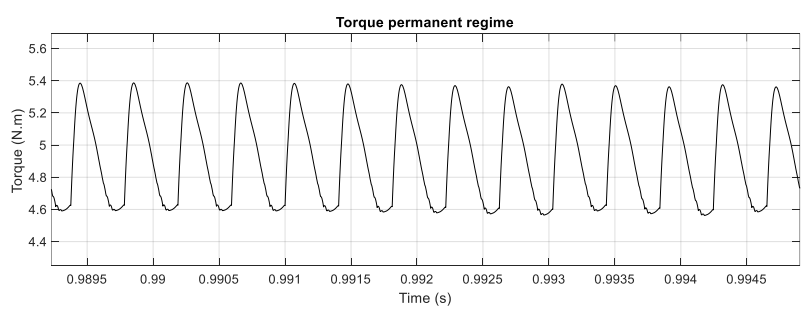

Fig. 10. Steady state torque.

Fig. 6. Diagram of the current controller block for a phase. 
Another greatness also obtained during the computational implementation and of relevance is the flow in the phases of the motor, in figure 11 we have the representation of this greatness.

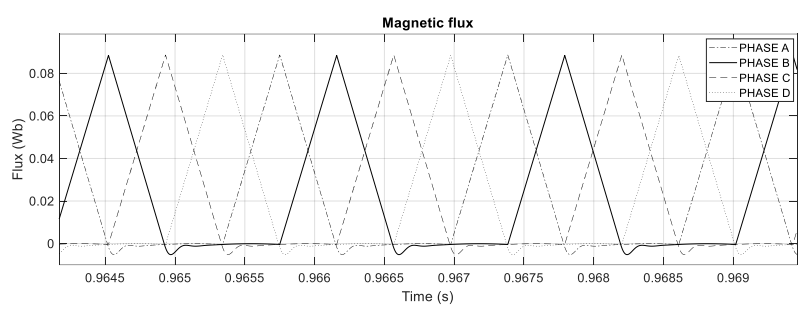

Fig. 11. Magnetic flux permanent regime.

At the end we have the efficiency of the motor by its speed. The resulting efficiency graph is shown in figure 12, demonstrating that the motor efficiency is not uniform over its operating range.

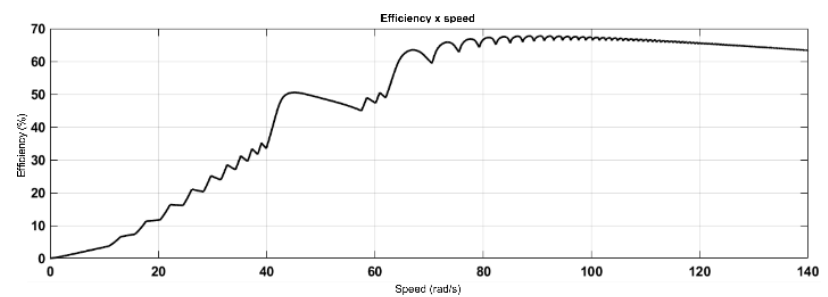

Fig. 12. Efficiency x speed.

One of the advantages of Switched Reluctance Motor, which is the possibility to operate even with phase failure. In Figure 13 the machine is shown operating at approximately $30 \%$ of the nominal load and in the half-time of the simulation a phase was broken, showing that the machine is still in operation with the efficiency undergoing a slight change. Thus, with a small oscillation.

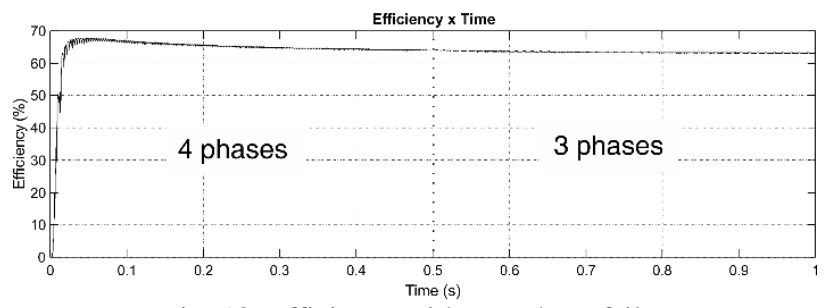

Fig. 13. Efficiency with one phase failure.

\section{Conclusion}

In this work a computational platform was presented for the study and drive of a Switched Reluctance Machine 8x6 operating as a motor, including its operating principle along with its elementary equations. Analysing the results obtained through the computer simulation, it was verified that the SRM $8 \times 6$, presented characteristics such as: oscillatory torque, coming from the topology of the used activation system and the constructive characteristics of the machine and quite high current requested when the machine starts, requiring optimization the activation system in order to maximize efficiency. Looking at the scenario of energy efficiency together with renewable energies the development of a machine activation to Switched Reluctance Machine 8x6 operating as a motor shows a promising study considering its advantages as: possibility of direct power supply in direct current, tolerance to lack of phases, can be used in cars and buses in a hybrid way and also changing their behaviour as generator or motor depending on the application.

\section{Acknowledgement}

The authors would like to thank Federal Institute of Education, Science and Technology Goiás - Campus of Itumbiara for the contribution.

\section{References}

[1] Miller, Timothy John Eastham (Ed.). Electronic control of switched reluctance machines. Elsevier, 2001.

[2] Oliveira, D. N. Proposta e Implementação de Sistema para Caracterização Eletromecânica Estática e Dinâmica de Motores Rotativo e Linear de Relutância Chaveada. 2008. Dissertação (Mestrado em Engenharia Elétrica.) Dissertação de mestrado, Universidade Federal do Ceará-Brasil.

[3] Moraes, Marcos José et al. Proposta de Plataforma Ppara Estudo de Motor A Relutância Variável 8/6.

[4] Riley, Chris P. et al. Simulation based design of reluctance motors for traction applications in hybrid and electric vehicles. In: Power Electronics, Machines and Drives (PEMD 2014), 7th IET International Conference on. IET, 2014. p. 1-6.

[5] Sun, M. et al. Design and Optimization of Switched Reluctance Motor for Propulsion System of Small Electric Vehicle. In: Vehicle Power and Propulsion Conference (VPPC), 2016 IEEE. IEEE, 2016. p. 1-5.

[6] Nidec, http://www.srdrives.com/land-rover.shtml, acessado em 13/10/2018.

[7]Drives\&Controls.http://drivesncontrols.com/news/fullstory.p hp/aid/3872/Switched reluct ance motors power electric Land Rovers.html, acessado em 13/10/2016.

[8] Nidec, http://www.srdrives.com/green-propul sion.shtml, acessado em 13/10/2018

[9] Nidec, http://www.srdrives.com/starter-generator.shtml, acessado em 13/10/2018.

[10] Silveira, A. W. F. V. Controle de tensão na carga para motor/gerador a relutância variável de três fases. 2008. 165 f.. Tese (Doutorado em Engenharia Elétrica.) - Faculdade de Engenharia Elétrica, Universidade Federal de Uberlândia, Uberlândia, 2011

[11] B. Fahimi, et. al., "A switched reluctance machine-based starter/alternator for more electric cars" Trans. Energ. Conver., vol. 19, $n^{\circ} 1$, Março 2004.

[12] Cai. W, "Comparison and review of electric machines for integrated starter alternator applications," IEEE - IAS, 2004. Vol. 1, Outubro de 2004 